\title{
Bases Sociais e Intérpretes da "Tradição Trabalhista" no Rio Grande do Sul
}

Igor Gastal Grill

\begin{abstract}
s narrativas de consagração do trabalhismo efetuadas por prota$\mathcal{1}$ gonistas políticos encarregados e interessados na eternização da "tradição política" são elementos de fixação de identidades e de explicitação de rivalidades e alinhamentos. As estratégias de ativação, apropriação e transmissão de valores, ícones e símbolos que conferem sentido à idéia de continuidade constituem importantes veículos de formação de uma comunidade afetiva (Halbwachs, 1994), mas revelam também o processo de disputas e negociações relativas ao uso da memória política (Pollak, 1989). O foco deste artigo está centrado nas disputas, invenções e reinvenções da "tradição trabalhista" no Rio Grande do Sul.
\end{abstract}

A utilização do passado trabalhista na política contemporânea gaúcha pós-regime militar não pode ser caracterizada simplesmente como um trabalho de memória institucional e oficial (integrante da memória consagrada pelo Estado), nem tampouco como uma memória subterrânea silenciada durante décadas que emerge em um novo cenário histórico. Porém, essa utilização da memória possui elementos que aproximam duas modalidades de enquadramento da memória identificadas por Pollak (idem). Por um lado, o "legado getulista" - e, por conseqüência, a a propriação trabalhista feita dele - contém fatores de identificação que remetem à construção da memória nacional por meio da

DADOS - Revista de Ciências Sociais, Rio de Janeiro, Vol. 48, n3, 2005, pp. 525 a 557. 
consagração, nos discursos oficiais, do dirigente político e estadista. Por outro, tais elementos se fundem, no Rio Grande do Sul, com as narrativas de lutas e resistências que atravessaram o século $X X$, produzindo "heróis" que ascenderam politicamente, enfrentando eleitoral e militarmente inimigos políticos.

A partir do final da década de 1970, o padrão de celebração dos ícones da "tradição" ganha novo impulso, depois de duas décadas de regime militar. Os políticos identificados com o trabalhismo, que militaram no $\mathrm{MDB}^{*}$ e foram cassados ou exilados, transmitiram suas lembranças no quadro familiar e nas redes de sociabilidade afetiva e política ${ }^{1}$. Contudo, não se pode sustentar que essas lembranças fossem "proibidas", "indizíveis" ou "vergonhosas"; elas apenas formavam um estoque de referências cuja utilização pública exigia triagens, sínteses e omissões e relegava a valorização e enunciação de determinados eventos, símbolos e ícones ao lugar de lembranças "zelosamente guardadas em estruturas de comunicação informais" (idem:8). A emergência de uma conjuntura favorável, com a abertura política e a reintegração dos principais quadros do trabalhismo na cena política nacional, configura a ocasião para que parte dessa memória se situe novamente no espaço público, inclusive como objeto de disputa.

Uma série de agentes e partidos se autorizou, através de itinerários e recursos distintos, para acionar essa memória. Esse trabalho de memória inclui a utilização do passado como estratégia de garantir não só a coesão das coletividades e a complementaridade entre as partes, mas também as "oposições irredutíveis" (idem:9). Tal esforço está presente nas práticas que visam homenagear e redefinir o "espólio político".

A ativação do passado é, assim, obra de múltiplos agentes e instituições que estabelecem simultaneamente quadros de referência e um trabatho de enquadramento. Os quadros de referência são os sentidos a serem disputados e sobre os quais se alicerça o "passado comum", definindo as fronteiras sociais e políticas que circunscrevem os postulantes à herança. Como tal, não sucumbem à arbitrariedade dos discursos, pois exigem a justificação das práticas e dos usos, assim como impõem o "imperativo da coerência" nos discursos sucessivos. Como sustenta Pollak:

\footnotetext{
* Ver lista de siglas de partidos políticos com os respectivos significados ao final do artigo.
} 
“O trabalho de enquadramento da memória se alimenta do material fornecido pela história. Este material pode sem dúvida ser interpretado e combinado a um sem número de referências associadas; guiado pela preocupação não apenas de manter as fronteiras sociais, mas também modificá-las, esse trabalho reinterpreta incessantemente o passado em função dos combates do presente e do futuro. Mas assim como a exigência de justificação [...] limita a falsificação pura e simples do passado na sua reconstrução política, o trabalho permanente de reinterpretação do passado é contido por uma exigência de credibilidade que depende da coerência dos discursos sucessivos". (idem:10)

Além disso, nesse processo de invenção, recepção e apropriação da herança, a consagração dos heróis da "tradição política" desempenha papel primordial. É pela proximidade e pela lealdade demonstrada que os candidatos a sucessores buscam justificar sua pretensão a tal posto, propagando, para tanto, sinais e imagens capazes de associá-los aos líderes que compõem as referências comuns. Como indica Coradini, estão em jogo, nessas disputas e homenagens, além de lutas políticas, “os princípios de aferição da excelência 'humana' e, portanto, de hierarquização social" (1998a:211-212). Os heróis celebrados encarnam os recursos sociais e culturais dominantes e extraordinários, os valores culturais passíveis de conferir um conteúdo de canonização e a busca de um sentido para a luta política, mediante o reconhecimento e a identificação nas relações sociais e nos esquemas de classificação acionados.

Este artigo segue algumas diretrizes apontadas por Coradini (idem:227-229) para o cenário sul-rio-grandense no que diz respeito às modalidades de legitimação presentes na associação com o passado e na eficácia política dessa associação. Em primeiro lugar, a localização fronteiriça do estado, a herança do caráter escravista e hierarquizado da sociedade gaúcha - na qual o exercício da dominação se realizava através das armas -, e as guerras de facções que marcaram os conflitos políticos são aspectos que contribuem para a construção da imagem dos "heróis militares". Em segundo lugar, a emergência de setores da "pequena burguesia" dotados de capital cultural e integrados por descendentes de famílias de imigrantes se reflete nos investimentos que visam à "reafirmação e redefinição da identidade étnica", e na criação de uma "nova simbologia" que exalta a "ideologia do trabalho" e da "ascensão social". Em terceiro lugar, a expansão das vias de escolarização e a propagação de "ideologias e posições ditas de esquerda" repercutiu na afirmação de novos mediadores e na proliferação de reinter- 
pretações da história local e de invenções de "novas mitologias". Para Coradini (idem:232), o processo de transmissão do "poder político" em condições periféricas como as do contexto brasileiro, e especificamente o gaúcho, se dá mediante uma concepção de política que combina o princípio da "reciprocidade" ou do "dom" com a personificação de "qualidades". Por conseguinte, a concepção social hierarquizante e a naturalização da diferenciação entre representante e representado, bem como o peso dos princípios de legitimação carismática e da personificação dos trunfos, criam as condições de transmissão através da fidelidade do séquito e pela encarnação do carisma. As tentativas dos "candidatos a herdeiros" de estabelecer uma maior ou menor proximidade social e ideológica com os líderes e heróis consagrados, pautadas nas dinâmicas sociais e nos princípios de hierarquização elencados acima, conformam as disputas pelas "heranças", a apropriação dos "legados" e a perpetuação dos patrimônios.

Nessa dupla vinculação (ao líder heroicizado e aos critérios de seleção em pauta) age também o que Hélias (1979:747) denominou troca simbólica, envolvendo as homenagens aos mortos. Instaura-se, para o morto, uma condição de credor e, para os vivos, uma condição de devedores. A homenagem, como sinal de gratidão, não é correlativa à dívida estabelecida e, por isso, não encerra a reciprocidade exigida dos vivos em relação aos mortos. Como afirma Hélias: “A troca simbólica não contém nenhuma reciprocidade que possa ser dissolvida, uma vez que se encontra desestabilizada entre um crédito que sempre pode se avolumar e uma dívida impagável dos devedores" (idem:749). Isso decorre do fato de a fonte da dívida residir na "vida dada" pelo morto (credor) e da necessidade dos vivos cumprirem a sua missão - a dívida só deixa de existir com a morte desses últimos. A eficácia ideológica das homenagens reflete-se na "valorização da morte guerreira", incidindo na valorização dos personagens e nos modelos de condutas a serem seguidos pelos vivos. Portanto, as homenagens e "resgates" aqui analisados adquirem o conteúdo de reafirmação da lealdade por meio do reconhecimento da dívida. Afora isto, são modalidades de afirmação do "lega$\mathrm{do}^{\prime \prime}$, externalizando a crença na herança como um patrimônio a ser gerido, o culto à memória comum como identidade coletiva e a renovação da filiação aos signos que atestam a continuidade.

Os protagonistas engajados no culto à "tradição", à herança, à memória, à filiação etc. maximizam, nas lutas políticas e eleitorais, sua inscrição nesse "legado". Conforme Coradini: "dependem diretamente da 
eficácia de elaboração e difusão de imagens sociais e, assim, a própria imagem pode ser herdada por associação ou aproximação com heróis já consagrados" (1998a:232). Os usos da memória, porém, não se resumem a essas associações ou aproximações propagadas, mas também às alianças horizontais e verticais que possibilitam no presente, e às dívidas de reciprocidade e lealdade que estabelecem para o futuro. Entre as formas de captar tais estratégias, optou-se pelo exame de produções escritas (livros, artigos e textos) de homens políticos que visam a "resgatar" o "legado" e inscrever os agentes em sua "genealogia".

A utilização adotada aqui de invenção da tradição segue o tratamento dado por Neiburg, segundo o qual o uso da expressão invenção

"[...] nada tem a ver com um juízo acerca da artificialidade das interpretações, menos ainda com qualquer suposto a respeito da liberdade ou da eficácia das vontades individuais na construção dos fatos sociais [...], busca simplesmente acentuar uma perspectiva não substancialista, atenta à dimensão produtiva das ações sociais sobre a 'realidade' social" (Neiburg, 1997:16).

A "tradição política" revelada nos debates e conflitos, por sua vez, permite ao pesquisador apreender "a gênese dos agentes sociais que se constituíram por meio deles, as instituições a partir das quais falaram, as formas de produção cultural que procuraram consagrar" (idem:16).

Para apreender como o trabalhismo se transformou em objeto de debates e disputas entre atores que procuraram se inscrever nessa história, é importante pôr em relação alguns dos seus intérpretes, analisando as bases sociais da sua militância e os alinhamentos políticos que efetuaram. Neste artigo, examinam-se três formas de avaliar o "legado trabalhista", suas origens, seus conteúdos e sua natureza. As perspectivas sustentadas por atores políticos que optaram pelo PDT, pelo PMDB e pelo PT condensam alguns dos repertórios de identificação existentes, indicam as bases de mobilização da agremiação e do seu líder, revelam as estratégias de afirmação dos autores no interior da sua facção política e sinalizam os princípios de hierarquização social e política em luta e as bases culturais de sua legitimação.

A diversidade das opções partidárias dos quadros políticos que reivindicam de alguma forma a continuidade da "tradição trabalhista" traduz três processos interligados. Em primeiro lugar, as fidelidades ou disputas fomentadas ainda no PTB, renovadas no interior do MDB 
e/ ou transmitidas a este e que emergiram novamente, com maior nitidez, na divisão entre PMDB e PDT e também entre o PMDB e o PT. Em segundo, as redes de lealdade e as clivagens construídas no interior do $\mathrm{MDB}$, que pautaram as escolhas pelas novas siglas, bem como condicionaram a manutenção de bases políticas, o reingresso na arena eleitoral (sobretudo para cassados e exilados) e a emergência de novas lideranças $^{2}$. Em terceiro, os princípios concorrentes de hierarquização social e de critérios de aferição da "excelência humana" em pauta no contexto sul-rio-grandense, que são reconvertidos para o espaço político e criam afinidades entre homens políticos, funcionando como parâmetros para a reconstrução da "tradição", para a heroicização dos ícones e para a localização de diferentes correntes políticas (ou siglas) e de seus líderes, como continuadores do "legado".

Serão analisados textos produzidos por três agentes que se lançaram no esforço de interpretar a "tradição" e seu "legado", logo situando-se entre os pretensos herdeiros da mesma, cotejando-se as leituras produzidas sobre o trabalhismo presentes em dois livros escritos por Miguel Bodea $(1979 ; 1992)$, na apresentação de Pedro Simon (1994) a uma coletânea de textos de Alberto Pasqualini organizada por Simon e, finalmente, em três artigos de Tarso Genro (1976a; 1976b; 1976c), lançados durante a década de 1970 em um "jornal alternativo" dirigido a militantes de esquerda. Ao apresentar as narrativas de Miguel Bodea, Pedro Simon e Tarso Genro, não se pretende contemplar o conjunto de leituras possíveis, mas antes proceder no sentido de revelar "a definição do objeto de referência [...], a identidade social de cada sujeito debatedor [...] e as várias expectativas de cada um deles nas relações entre objeto e sujeito" (Neiburg, 1997:46). Há, entre eles, o reconhecimento mútuo acerca da autoridade pessoal e política de cada um para expressarem, como porta-vozes de uma "corrente de opinião", uma leitura sobre o objeto; compartilham, igualmente, a crença no "legado" e nos seus elementos formadores e comungam o sentido de "resgate" como fundamentação das tomadas de posição nas lutas políticas contemporâneas. Ao perseguir os argumentos de autoridade desses protagonistas, é possível captar não só os recursos e as lógicas legitimadores da posição social dos agentes e instituições que reinterpretam a "tradição política", como também o espaço social e cultural que deu origem a essa tradição e fez emergir os agentes a ela identificados.

A seguir, são examinadas as narrativas desses atores à luz das suas origens sociais, dos seus recursos pessoais e das suas fidelidades políti- 
cas. Os três intérpretes apresentam origens diferentes para o trabalhismo ("positivismo castilhista", "catolicismo pasqualinista" associado ao "nacional-desenvolvimentismo varguista" e "populismo"), selecionam a centralidade de alguns vultos, estabelecem uma triagem entre os elementos a serem apropriados nas lutas futuras, nomeiam as correntes políticas (o "socialismo democrático" do PDT, a "socialdemocracia" com componentes de "solidarismo cristão" do PMDB do Rio Grande do Sul e o "socialismo" em uma vertente que reivindica a centralidade do "método científico marxista") e os atores responsáveis pela gestão do patrimônio ou por sua superação (o que não deixa de significar continuidade), e se inscrevem nessa "tradição". Ao mesmo tempo, convergem sobre elementos como o "projeto de desenvolvimento", o "nacionalismo como bandeira", a bifurcação originária entre os dois fundadores (Vargas e Pasqualini), o "legado" da valorização partidária e a crença na especificidade da política regional como "raiz" da particularidade das formas de fazer política no Rio Grande do Sul.

\section{MIGUEL BODEA E O PDT: VALORIZAÇÃO DO POSITIVISMO, AFIRMAÇÃO INTELECTUAL E "RETOMADA DO FIO DA HISTÓRIA"}

A versão mais difundida e dominante acerca do "espólio" trabalhista sustenta a centralidade de Leonel Brizola como herdeiro de Getúlio Vargas e João Goulart. Contribuem, para tanto, o itinerário construído pelo personagem e as leituras retrospectivas feitas sobre ele, assim como o proselitismo dos seguidores do seu projeto partidário, o PDT. A seguir são demonstrados alguns elementos importantes presentes na sua trajetória e o trabalho de "resgate" e de localização de Leonel Brizola, do PDT e dos seus adeptos nesse continuum histórico desempenhado por um dos seus seguidores, Miguel Bodea.

Leonel Brizola obteve êxito em se constituir como continuador da "tradição" que se iniciou com Getúlio Vargas e teve prosseguimento com João Goulart. À vinculação pessoal e familiar que conquistou junto aos líderes da "linhagem", somou a construção do carisma com base em uma biografia de ascensão social e de realizações "heróicas". Começou a exercer sua liderança estudantil no Centro de Estudantes Universitários de Engenharia - CEUE da Faculdade de Engenharia do Rio Grande do Sul, ingressando na militância partidária por meio da Ala Moça do PTB. De seu itinerário político até a instalação do regime militar constam os seguintes cargos: eleito deputado estadual constituinte em 
1947; reeleito em 1950 (o mais votado no PTB) e escolhido líder da bancada; candidato derrotado à prefeitura de Porto Alegre em 1951; secretário de Obras do governo de Ernesto Dornelles; deputado federal em 1954 (o mais votado do estado); prefeito de Porto Alegre em 1955; governador do Rio Grande do Sul em 1958; líder do Movimento da Legalidade em 1961; deputado federal pelo Rio de Janeiro em 1962; político cassado pelo regime militar. A capacidade de "comunicação com as massas" e a "competência administrativa", bem como o cunho social e nacionalista dos programas que desenvolveu, são elementos articulados à sua imagem. Além disso, a ligação pessoal com Getúlio Vargas e o vínculo familiar com João Goulart (por meio do casamento com uma de suas irmãs) são elementos decisivos.

O percurso de Leonel Brizola e a apresentação dos seus trunfos permitiram que, no momento do golpe militar, sua liderança como um dos protagonistas do trabalhismo no Brasil estivesse consolidada. No interior do PTB, contou com os elos pessoais mantidos com Getúlio Vargas e João Goulart, sedimentados mediante posicionamentos e alinhamentos que demonstravam fidelidade e reforçavam as alianças. Contudo, sua afirmação e ascensão política se apóiam igualmente na construção do seu carisma. Somou a construção da figura do político responsável pela seqüência da "tradição de enfrentamentos" (inclusive armados) celebrada no Rio Grande do Sul à inscrição pessoal (política e familiar) na "linhagem". Ademais, fixou o "estilo de comunicação" com os eleitores invulgares, marcado pelo "didatismo" e pela "linguagem acessível", assim como pela utilização de meios inovadores para o proselitismo político, principalmente o rádio e mais adiante a televisão. Ademais, foi capaz de combinar, em seu itinerário pessoal, a origem familiar ligada às lutas políticas e militares do Estado, a conquista de títulos escolares e posições políticas de destaque (inclusive no plano nacional) a partir de uma "origem humilde", e a constituição de um perfil de político "planejador" e voltado para as "questões sociais" e as "bandeiras nacionalistas". Essa concordância de trunfos provenientes de origens diversas se mostrou decisiva nos embates externos e principalmente nas lutas internas ao PTB e à "família política", notadamente aquelas travadas com José Diogo Brochado da Rocha e Fernando Ferrari no período que se encerra em 1964, e com Pedro Simon e Ivete Vargas no período que se inicia em 1979.

Cassado em 1964 e exilado durante o regime militar, organizou ainda focos de resistência armada a partir do Uruguai. A morte de João Gou- 
lart em 1976 e a perspectiva de reabertura política avistada na segunda metade da década de 1970 convergem para a transmissão da "herança" e para a ativação da memória política. A estratégia de reconstrução do PTB e sua liderança no futuro partido ampararam-se na biografia pessoal do líder e na idéia de continuidade do trabalhismo. Nesse processo, dois personagens se constituíram em adversários e concorrentes na disputa pelo "legado trabalhista": Ivete Vargas e Pedro Simon. Os trunfos acionados por ambos são elucidativos da disputa pelo uso do passado como um recurso político. Ivete Vargas aliou às suas redes de relações no governo federal o uso do sobrenome e do parentesco, que a ligavam a Getúlio Vargas, para disputar a legenda, obtendo êxito. Pedro Simon utilizou o papel desempenhado como líder do MDB (sigla que abrigou os trabalhistas durante o regime militar) no Rio Grande do Sul para mobilizar os quadros que se auto-intitulavam trabalhistas no sentido de permanecerem no PMDB, no estado considerado "berço do trabalhismo".

A pós perder a legenda, Leonel Brizola fundou o Partido Democrático Trabalhista, que teve como móbil de identificação o esforço de mostrar que o partido era o elo possível com a "história trabalhista" nele mesmo encarnada. Acrescente-se a isso o período de exílio e a circulação internacional, que lhe permitiram constituir uma rede de contatos com líderes socialistas e socialdemocratas de várias partes do mundo, fazendo que a imagem do líder contivesse, em um só golpe, o potencial político de um "mobilizador das massas" e a disposição para o combate, certificados pela "origem" e pela "biografia", os quais se somavam ao trânsito internacional. Esses elementos colaboram para a afirmação da figura do "homem político" inscrito no padrão de legitimação local condizente com a "história gaúcha", padrão dotado de exemplaridade e marcado pela composição de lógicas regionais, nacionais e internacionais na encarnação de um "projeto". Assim, elegeu-se duas vezes governador do Rio de Janeiro e disputou em duas ocasiões a presidência da República (sem sucesso) pelo PDT ${ }^{3}$.

Miguel Bodea nasceu em Minas Gerais. Oriundo de um grupo familiar com significativos investimentos escolares, é filho de diplomata, e sua irmã, Bárbara Freitag, é doutora em sociologia (identificada com o marxismo) e professora aposentada da Universidade de Brasília UnB. Bodea estudou no Colégio de Aplicação da Universidade Federal do Rio Grande do Sul - UFRGS, formou-se em economia em Cambridge (Inglaterra) e obteve o título de mestre em ciência política pela Uni- 
versidade de São Paulo - USP. Sua circulação internacional possibilitou, além da formação em economia, a participação em institutos de estudos ligados a partidos políticos, como o Partido Socialdemocrata Alemão, e a conclusão de um curso de graduação em ciências sociais na École des Hautes Études en Sciences Sociales, em Paris. Aliou sua formação escolar a funções políticas, como as de assessor do MDB na Assembléia Legislativa do Rio Grande do Sul, na década de 1970, e do governador do Rio de Janeiro pelo PDT, Leonel Brizola, na década de 1980. Tais inserções contribuíram para sua "liderança política e intelectual" no Brasil, onde foi um dos idealizadores do Instituto de Estudos Políticos, Econômicos e Sociais - IEPES do MDB e consultor do Instituto Latino-Americano do Desenvolvimento - ILDES, órgão vinculado à Friedrich Ebert-Stiftung (instituição alemã ligada à socialdemocracia).

O acesso e o contato com líderes da socialdemocracia européia e sua militância dentro do trabalhismo são registros que se mesclam na legitimação das suas tomadas de posição. A opção pelo PDT, com a reorganização partidária pós-regime militar, se alicerça nos vínculos anteriores cultivados (como assessor da bancada do MDB) e na aproximação da sigla e de seu líder com dirigentes (Mário Soares, Willy Brandt, François Miterrand, entre outros) e organismos classificados como socialdemocratas ou socialistas. Sua contribuição e sua relevância política se amparam nos títulos, laços e competências para reinterpretar a "história do trabalhismo" sob o duplo registro de continuidade com a "tradição política gaúcha" (leia-se positivismo) e de formulação de um "projeto político" (o PDT de Leonel Brizola).

Os prefácios a seus dois livros que tratam do tema são elucidativos. Otávio Caruso Brochado da Rocha - filho e sobrinho de lideranças do PTB e neto de um líder do PRR -, considerado um dos principais dirigentes e "teóricos" do trabalhismo, saudou a publicação do ensaio de Miguel Bodea intitulado A Greve Geral de 1917 e as Origens do Trabalhismo Gaúcho (1979). No prefácio, enfatiza os títulos escolares do autor e sua dedicação à "práxis política [...] na qualidade de assessor das oposições gaúchas" (Brochado da Rocha, 1979:7). Identifica a origem da "motivação" do autor no "pulsar das bases oposicionistas gaúchas" e na sua necessidade de entender por que "ressoava em todos [...] a carta-testamento de Getúlio? Ou perpassava nas concentrações partidárias o pensamento de Pasqualini e a tragédia de Jango? Ou estrugiam nos comícios as ovações permanentes a Brizola?" (ibidem). Além disso, 
justifica a relevância da pesquisa pela centralidade que nela assume a figura de Getúlio Vargas, como "ponte" entre períodos históricos e partidos (PRR e PTB), acrescentando: “Não se trata contudo de arqueologia política, mas de pesquisa a viver para o futuro, pois Getúlio ainda vive, pela carta-testamento, tanto no afeto das massas quanto na consciência do povo exilado" (Brochado da Rocha, 1979:9).

José Álvaro Moisés, por sua vez, em prefácio ao livro de Bodea publicado com o título de Trabalhismo e Populismo no Rio Grande do Sul (1992), definiu tal esforço como resultante da crença na "continuação de uma experiência correta de mudanças sociais, no caso, o PDT de Leonel Brizola" e de seu esforço, realizado "com grande eficiência e sentido profissional", para "fazer a ligação entre movimentos sociais e políticos locais com seus congêneres europeus, no caso, com tendências da socialdemocracia européia, mesmo quando os grupos nacionais não tinham nenhuma ligação com o PDT" (Moisés, 1992:13).

A leitura das origens, da especificidade do "legado" e do percurso do trabalhismo feita por Bodea permite perceber uma das modalidades de estratégias de definição identitária da rede política liderada por Leonel Brizola e suas ramificações, mediante o trabalho de memória e as justificativas para suas tomadas de posição. A interpretação dada estabelece a associação de repertórios que condensam a "herança" em pauta, como sinônimo de "resgate" e de "evolução", ao mesmo tempo em que relaciona os investimentos escolares e militantes do autor, visando a valorizar seus recursos pessoais, sua biografia e suas possibilidades de intervenção.

Coradini já demonstrara que, na sustentação por Bodea da tese de que o trabalhismo seria o "herdeiro" do positivismo, "se trata, simultaneamente, da legitimação de um processo, visto teleologicamente, a formação do trabalhismo, e da posição do 'intelectual' que o apresenta" (Coradini, 1998b:118). Nessa estratégia, é acionada a "analogia entre 'positivismo' e 'modernização', em oposição ao tradicional" e a vinculação entre "esquerda" e "positivismo" como algo moderno (idem:121). Da mesma forma, posições relativas ao regionalismo reaparecem sob a "idéia de 'peculiaridade' positiva na história política regional" e os embates entre "positivistas" e "católicos" são lidos pelos alinhamentos partidários "imersos numa lógica evolutiva teleologicamente pressuposta" (idem:122). 
Os dois textos escritos por Miguel Bodea sistematizam sua leitura sobre a "história do trabalhismo". Baseados na mesma idéia central, aquela que afirma a continuidade entre o "republicanismo castilhista" e o "trabalhismo", os ensaios oferecem elementos de fixação da persistência de linguagens e valores na passagem do positivismo de Júlio de Castilhos e Borges de Medeiros para o trabalhismo de Getúlio Vargas e Alberto Pasqualini, sem deixar de apontar seus desdobramentos e invariâncias nas gerações subseqüentes (como em João Goulart, Leonel Brizola e seus seguidores).

No primeiro trabalho, Miguel Bodea parte da greve geral ocorrida em 1917 - durante uma das gestões de Borges de Medeiros à frente do executivo gaúcho - e pretende explicar "as razões" que levaram a "elite política gaúcha" a "desempenhar um papel de relevo na Revolução de 1930 e nos processos políticos que desembocariam no chamado 'ciclo de Vargas' da história republicana" (Bodea, 1979:17). Os posicionamentos de Borges de Medeiros perante o movimento grevista são avaliados pelos conteúdos das iniciativas (linguagem incomum entre as elites da República Velha) e pela "rapidez" (Bodea chega a supor que os decretos estavam prontos mesmo antes da eclosão do movimento) com que atendeu grande parte das reivindicações (idem:37). Na argumentação de Bodea, as medidas tomadas por Borges de Medeiros configurariam "uma nítida intervenção no mercado, contrariando as normas do laissez-faire, laissez-passer defendidas pelo liberalismo clássico" (idem:39). A adoção de uma "aliança de cima para baixo" estaria amparada na doutrina "hegemônica" no PRR: o positivismo. Na reconstrução de Bodea, "intervenção estatal" e "aliança com o operariado" são elementos estabelecidos no seio da cúpula do partido e "prenunciam [...] o ideário que caracterizaria o trabalhismo gaúcho" (idem:41). A seguir, Bodea classifica o evento como "um pré-ensaio do fenômeno populista e, mais especificamente, do trabalhismo, principalmente na sua variante gaúcha" (idem:45), identificando nos documentos a afirmação do "pioneirismo regional [...] de uma doutrina e uma práxis [...] em termos quase proféticos [...] predestinados a se generalizarem a nível nacional" (ibidem).

Outro componente "ideológico permanente", o nacionalismo, seria adicionado à "crítica ao liberalismo" e à "questão social". E, para comprovar as origens republicanas e castilhistas do trabalhismo, Bodea utiliza o desfecho de outra greve, ocorrida também em 1917, promovida por ferroviários, que culminou com a estatização da Viação Férrea 
do Rio Grande do Sul - VFRGS, até então controlada por uma concessionária belga. Tal episódio é interpretado como uma nova manifestação do tipo de "aliança de cima para baixo" patrocinada pelo PRR, e mais uma vez são projetadas semelhanças com posicionamentos futuros: “É [...] notório o parentesco entre a linguagem dos boletins grevistas de outubro de 1917 e a linguagem que caracterizaria o trabalhismo getulista várias décadas mais tarde, sintetizada [...] na carta-testamento de Vargas" (Bodea, 1979:60).

A perenidade desses códigos é acompanhada da apresentação de um personagem responsável tanto pela tarefa de perpetuar tais valores e símbolos quanto de renová-los e "projetá-los" nacionalmente. Bodea situa, dessa forma, o papel de Getúlio Vargas no interior de um processo de sucessão política no qual "Borges, a exemplo do que lhe fizera Júlio de Castilhos ao passar-lhe o cetro da liderança republicanopositivista, precisava ungir um herdeiro de comprovada fidelidade. Sua escolha recaiu sobre Getúlio Vargas" (idem:86). A apropriação da herança é legitimada pelo protagonista, que relata o processo através de um duplo movimento: sinais de continuidade em relação à "tradição" e demonstração de competência (biografia e habilidades) para administrar e renovar o estoque de códigos de adesão. Bodea enfatiza, nesse momento, a participação destacada de Getúlio Vargas em lutas armadas em que os republicanos se envolveram e a sua experiência como negociador, conquistada no exercício dos cargos de deputado federal e de ministro da Fazenda. Além disso, classificando o líder político simultaneamente tanto como depositário dos códigos de disciplina e fidelidade que marcam a sua "tradição partidária" quanto dos recursos de trânsito que fixam a capacidade de negociação e de estabelecimentos de alianças, procura demonstrar a "pré-aptidão da elite gaúcha para o exercício do poder nacional" (idem:87).

A referência ao personagem mítico singularizado por qualidades excepcionais é reforçada pela exemplaridade desse em personalizar e maximizar trunfos e características, lidos como decorrentes da especificidade regional e da "pré-aptidão" desfrutada por uma geração de quadros políticos formados no PRR. Bodea sintetiza seu argumento defendendo que os positivistas haviam formulado "de forma embrionária" experiências que vieram a se generalizar no país, identificando a "herança positivista" na legislação trabalhista e em um "novo modelo de desenvolvimento nacional", que incluiria a "mobilização dos tra- 
balhadores" e a "bandeira do nacionalismo e do desenvolvimentismo" (idem:93).

Em trabalho posterior, Bodea (1992) aprofunda suas teses. Apoiando-se nos conceitos de "intelectual orgânico" e de "hegemonia" de Gramsci e na noção de "interpelações democrático-populares" de Laclau, Bodea busca assinalar os mesmos elementos (aproximação com setores populares, nacionalismo, desenvolvimentismo, intervenção estatal e especificidade gaúcha) em um continuum que se estende da afirmação de Vargas e de sua "herança positivista", passa pela complementaridade ou divisão de tarefas entre Vargas e Pasqualini e chega à reprodução dessas funções, compartilhadas por João Goulart e Leonel Brizola.

A descrição da confluência de três vertentes na formação do PTB - denominadas por Bodea (1992:21) "corrente sindicalista", "corrente doutrinária-pasqualinista" e "corrente pragmático-getulista" - estrutura a articulação dos elementos selecionados pelo autor. Perseguindo o entrecruzamento entre tais vertentes, estabelece um modelo evolutivo no qual elas se integram no "PTB gaúcho". A articulação entre "elite política" (corrente pragmático-getulista), "setores populares" (corrente sindicalista) e condução de "intelectuais orgânicos" (corrente doutrinária-pasqualinista) possibilitaria a ligação com a "herança positivista" e a transmissão do "legado", que se encaminha para o nacionalismo e o socialismo ${ }^{4}$. Para ele, os futuros líderes do partido - entre eles os denominados herdeiros de Vargas e Pasqualini, João Goulart e Leonel Brizola - processariam "uma espécie de simbiose política entre as três vertentes formadoras do partido" (idem:45).

Na sua leitura, teria ocorrido, no seio do PTB do Rio Grande do Sul, uma "divisão de tarefas" entre Vargas e Pasqualini, os quais se diferenciariam e se complementariam, segundo ele, em relação à estratégia política (projeto nacional e projeto partidário), à esfera geográfica de atuação (nacional e regional) e à divisão de funções político-partidárias (estrategista político e doutrinador e teórico). O projeto político de Vargas é percebido com base em "tendências modernizantes", identificadas como o prosseguimento do "ideário positivista e castilhista". Nesse trabalho, Bodea situa Pasqualini nessa "tradição", afirmando que valores como "cooperação" e "equilíbrio social" seriam condizentes com a "mesma matriz que orienta o ideário de Vargas e seus principais companheiros da Revolução de 1930: o republicanismo 
castilhista do PRR, fortemente influenciado pelo pensamento positivista" (idem:153). Novamente, a triagem de elementos recai sobre a intervenção estatal, a crítica ao imperialismo e ao liberalismo e a mobilização popular. O caráter complementar da liderança nacional de Vargas e da liderança regional de Pasqualini é explicado com base no pressuposto da especificidade da política gaúcha: "maior organicidade e consistência dos partidos" e ocorrência de um "padrão de evolução histórica" (idem:173), pelos quais as lideranças são projetadas nacionalmente, estabilizando, em decorrência da experiência política ímpar que acumulam no plano regional, o sistema partidário. Em seguida, o autor projeta nas gerações futuras a possibilidade de ascensão a posições centrais e resguarda para as lideranças locais o papel de intérpretes e guardiões da "coerência ideológica". Encerrando, Miguel Bodea caracteriza a formação do partido político como resultado das tarefas doutrinárias e de produção de consenso "no momento da sociedade civil" (obra de Alberto Pasqualini) e de estratégia política "no nível do aparelho de Estado" (tarefa visualizada em Getúlio Vargas) (idem:181). A partir deles, Bodea procura afirmar o conteúdo "reformador" e "modernizante" do trabalhismo com "raízes" no "positivismo", o qual teria como padrão de "evolução" um "populismo operário e socialista", concepção que se contrapõe às interpretações negativas sobre o populismo.

É possível uma dupla linguagem de legitimação dos "herdeiros": 1) um elo estabelecido com o passado e 2) uma ruptura no processo de evolução que estava em curso. Assim sendo, observa-se a justificação e a valorização dos chamados herdeiros do trabalhismo da seguinte maneira: "os próprios herdeiros de Vargas e Pasqualini no trabalhismo, ou seja, Jango e Brizola, reproduzem [...] o padrão de divisão de tarefas característico das lideranças gaúchas" (idem:196). E a fundamentação e o "resgate" de um percurso "quebrado" aciona narrativas como esta: "A queda do regime constitucional provoca [...] uma quebra profunda no processo de evolução do trabalhismo de massas. [...] seria possível argumentar que o tempo histórico [...] foi insuficiente para o pleno desenvolvimento do trabalhismo" (idem:209).

A linguagem utilizada por Bodea nessa obra lança mão de termos como "caráter incomum" e "especificidade", os quais são vinculados aos de "prenúncio", "pré-ensaio", "parentesco" etc. Nessa combinação de "resgate" com tentativa de sistematização do "fio da história", Bodea sustenta a continuidade e a relevância do projeto político ao 
qual é filiado, assim como a centralidade do líder político ao qual é ligado, Leonel Brizola. Da mesma forma, ao conceber a "tradição política" como depositária de uma história regional ímpar e a complementaridade positiva entre "práxis" e "formulação teórica" afirma a sua posição nessa "genealogia".

\section{PEDRO SIMON E O PMDB: INFLUÊNCIA DO CATOLICISMO, AFIRMAÇÃO DO MDB E 0 "LEGADO PASQUALINISTA"}

O reconhecimento e a consagração dos "herdeiros" e da "tradição" são igualmente tributários dos trabalhos de apropriação e reivindicação do "legado" por parte de diferentes protagonistas, e dos conflitos que se estabelecem entre os porta-vozes do trabalhismo no Rio Grande do Sul, principalmente com aqueles classificados como dissidentes. Entre esses, os casos de maior notoriedade são os de José Diogo Brochado da Rocha, Fernando Ferrari e Pedro Simon. Os três apresentam carreiras intimamente ligadas ao antigo PTB e às suas vinculações com Getúlio Vargas e Alberto Pasqualini, assim como também disputaram, em diferentes momentos, o espólio do trabalhismo no Rio Grande do Sul. As origens familiares, os itinerários políticos e os desfechos, em termos das adesões conquistadas, sinalizam o entrecruzamento entre estrutura e bases do patrimônio político familiar, dos alinhamentos políticos, das inserções em redes, do cultivo de lealdades e dos trunfos pessoais de disputa política. Além disso, os três se associam de diferentes maneiras e com diferente intensidade à imagem dos ícones da "tradição". José Diogo Brochado da Rocha investiu, sobretudo, na proximidade social e política, como membro de uma "família" integrante dos círculos de elites sociais e políticas que precedem a redemocratização de 1945, e na antiguidade dos laços dele e de sua rede de parentesco com os adeptos do "varguismo". Fernando Ferrari e Pedro Simon apostaram na identificação com Pasqualini, ressaltando suas origens ligadas à imigração, sua vinculação ao catolicismo e seu itinerário social e político. Ao contrário de José Diogo Brochado da Rocha e Fernando Ferrari, Pedro Simon obteve sucesso como dissidente de Leonel Brizola no trabalhismo gaúcho. Para tanto, contou com a relação de parentesco por aliança com seu cunhado Siegfried Heuser, com a dissolução do PTB e a formação do MDB no regime militar e com o potencial de mobilização e de continuidade do trabalhismo que tornaram essa sigla um caso ímpar no país. 
Pedro Simon nasceu em 1930 e é descendente de imigrantes libaneses que chegaram à serra gaúcha em 1922. Filho de um mascate, oriundo de uma família profundamente vinculada ao catolicismo e que passou por significativa ascensão social, Pedro Simon tornou-se um líder estudantil, elegendo-se primeiramente presidente do grêmio do Colégio Rosário, em Porto Alegre, em seguida, do Diretório Acadêmico Maurício Cardoso na Pontifícia Universidade Católica - PUC-RS, chegando, posteriormente, à presidência de duas entidades nacionais: União Brasileira dos Estudantes Católicos - UBEC e União Nacional dos Estudantes - UNE. Nesse período já se identificava com Alberto Pasqualini (freqüentava reuniões na casa do irmão desse, Arlindo Pasqualini, juntamente com Otávio Caruso Brochado da Rocha e Flávio Ramos, entre outros, nas quais ouviam palestras do líder) e o acompanhou quando do ingresso da União Social Brasileira no PTB.

Em 1958, Simon defendeu, como líder da Mocidade Trabalhista, a candidatura ao governo do Estado de Loureiro da Silva, que concorria internamente, no PTB, com Leonel Brizola, em uma das primeiras demonstrações da rivalidade existente entre Simon e Brizola. Em 1962, concorreu a deputado estadual (foi o $19^{\circ}$ da bancada do PTB). Com a extinção dos partidos políticos, filiou-se e foi um dos organizadores do MDB, juntamente com Siegfried Heuser, Brusa Neto e Francisco Caruso Brochado da Rocha, entre outros. Reelegeu-se em 1966 e disputou, em Caxias, os votos pelo MDB com João Brusa Neto (líder sindical, jornalista, membro da União Social Brasileira e secretário particular de Alberto Pasqualini). Nessa legislatura, foram cassados, entre outros, João Brusa Neto e Siegfried Heuser. João Brusa Neto era um dos grandes líderes do trabalhismo em Caxias do Sul, e Siegfried Heuser era líder da bancada e presidente do MDB. Pedro Simon herdou o reduto do primeiro e a liderança do partido e da bancada do segundo.

Ungido sucessor de Siegfried Heuser na presidência do MDB e na direção da Ala Majoritária do partido ${ }^{5}$, Simon reelegeu-se deputado estadual em 1970 (o mais votado daquela legislatura) e em 1974 (novamente o mais votado). Em 1978 é alçado ao Senado. No final da década de 1970, entra em choque com Leonel Brizola, devido às divergências quanto ao destino partidário dos quadros identificados com o trabalhismo, o que culminaria na divisão entre o PMDB de Pedro Simon e o PDT de Leonel Brizola. 
Pedro Simon apoiou-se no capital político acumulado durante o período de bipartidarismo. Assim, já pelo PMDB, foi candidato a governador em 1982, ministro da Agricultura, governador do Rio Grande do Sul eleito em 1986, novamente senador em 1990 e 1998, líder do governo Itamar Franco no Senado e candidato à presidência do Senado. Em 2002, chegou a ser pré-candidato à presidência da República e à vice-presidência na chapa de José Serra. Mesmo com a cisão local, manteve sua liderança no Rio Grande do Sul e tornou-se uma das lideranças nacionais do PMDB.

A interpretação referente à "história do trabalhismo" e seu "legado" fornecida por Pedro Simon, como não poderia deixar de ser, tem como referência o próprio itinerário do "homem político". A sistematização do "resgate" e a definição da "herança" são explicitadas em texto intitulado "Pasqualini, o mestre e o exemplo" (1994), publicado como apresentação à obra Alberto Pasqualini: Obra Social e Política, uma coletânea de textos e discursos do líder partidário organizada por Pedro Simon. Na apresentação, Simon enfatiza, por um lado, aspectos já destacados por Bodea (1992): o papel de doutrinador e teórico (nesse caso chamado de "pregador" e "evangelizador") de Pasqualini; a importância que assumem, para tanto, suas duas campanhas ao governo do estado (1946 e 1954); o caráter complementar da sua liderança em relação à liderança de Getúlio Vargas ("pragmática"); sua "ideologia nacionalista" e a continuidade do "ideário", por meio da sua face partidária - o PTB -, considerada ímpar no país. Por outro lado, Simon aciona novas linguagens, e uma combinação distinta de elementos fundamenta a sua versão da apresentação do processo de afirmação e continuidade do trabalhismo, versão que situa a sua posição como intérprete e herdeiro da "tradição política". Nesse sentido, são destacados elementos não considerados ou tomados de forma periférica na leitura de Bodea (1992), como a influência da região de origem de Pasqualini (colonizada por imigrantes italianos); sua passagem pelo seminário católico e sua "formação cristã"; a defesa dos imigrantes e dos "pequenos colonos"; a compatibilidade entre catolicismo, trabalhismo e socialdemocracia; e os posicionamentos morais, como a valorização do trabalho e a condenação do "jogo", do "vício" e da busca de "vantagens pessoais". Além desses elementos, temas como a "batalha pela Petrobrás", a "defesa da reforma bancária", as formulações sobre assuntos ligados à economia (os juros e a inflação) e tomadas de posição sobre questões como o "poder militar", o "funcionalismo", as "leis", a "reforma agrária", a relação entre produtores e intermediadores, o "sistema econô- 
mico", a educação, a democracia e a imprensa são enunciados com base na opção partidária, nos posicionamentos conjunturais e nos valores éticos, religiosos e políticos do autor do texto.

A respeito da possibilidade de convivência de diferentes versões sobre o "fenômeno do trabalhismo e do populismo", Coradini (1998b:122) demonstra que, paralelamente a "leituras" como a de Bodea, que sustenta a continuidade entre positivismo, trabalhismo e socialismo, outras modalidades de apresentação são possíveis. Isto é, "com base nas versões do 'comunitarismo orgânico', é facilmente possível a defesa da idéia de que Pasqualini seria o resultado de sua formação católica [...] [ou] da incorporação de novos segmentos sociais não mais provenientes da 'campanha', mas das 'colônias' e, portanto, mais autênticas". Segundo Coradini, em ambas as versões, se observa "uma reivindicação, explícita ou não, de afiliações a 'heranças', daí o permanente sentido de 'resgate'" (ibidem).

O cotejo das versões produzidas por Miguel Bodea e por Pedro Simon revela mecanismos de afiliação e de "resgate" díspares e contrastantes, segundo as posições a partir das quais falam. Desse modo, Pedro Simon estabelece como fatores que influenciaram o pensamento de Pasqualini "a região em que nasceu" e sua formação com os "jesuítas do Seminário Nossa Senhora da Conceição" (Simon, 1994:20). Partindo dessas duas ligações, Simon expõe uma série de posicionamentos de Pasqualini, apresentando-o como o "intrépido defensor dos descendentes de italianos e alemães" (idem:27) que, por ser "filho do campo, jamais esqueceu os pequenos colonos" (idem:28). A "inclinação" para a justiça social estaria alicerçada, por sua vez, na "filosofia cristã". Sua formação religiosa é exaltada também como fonte da integração entre "humanismo", "solidariedade cristã" e "trabalhismo". Simon chega a afirmar que Pasqualini "demonstrou a coincidência do trabalhismo com as encíclicas papais" (idem:20). A orientação religiosa das suas tomadas de posição faz do "teórico do trabalhismo", na perspectiva desse intérprete, um personagem hábil e capaz de revelar sua "erudição" e utilizá-la para derrotar adversários políticos e sustentar seus posicionamentos políticos.

Dessa forma, são privilegiadas as passagens que associam o trabalhismo simultânea ou alternadamente ao catolicismo e à socialdemocracia. Segundo Simon, Alberto Pasqualini, "Socialdemocrata, na década de 20, antecipando-se em 70 anos à teoria dominante hoje na maioria 
dos países, passou toda a vida a pregar sua concepção de trabalhismo, muito próxima do solidarismo" (idem:23). Essa passagem mostra que, ao trabalho de "resgate", mistura-se o conteúdo de predição (tal como no relato de Bodea analisado anteriormente). Tanto no esforço de "reconstituição histórica" quanto na demonstração da qualidade de "visionário" do protagonista, é possível verificar o trabalho de seleção e triagem de símbolos.

As citações em que Pasqualini valoriza a formação do Partido Trabalhista Brasileiro, como "idéia" e "organismo político" capazes de "sobreviver aos indivíduos" (idem:26), e a "obra social" do presidente Vargas, pela qual "a idéia e a diretriz [...] devem ser continuadas, desenvolvidas e concretizadas" (idem:27), vinculam os personagens a uma mesma "tradição política" que se desdobra no tempo. O trabalho de "resgate" justifica-se na lógica do argumento pela contribuição que pode trazer às situações presentes e às gerações políticas em atuação. Do conjunto de artigos de jornais e pronunciamentos reunidos, Pedro Simon seleciona aqueles que avalizam seus posicionamentos pessoais e políticos nas últimas décadas. Sendo assim, consagra o "homenageado", revelando a "atualidade" das suas idéias e seu "pioneirismo" e "antecipação", ao mesmo tempo em que legitima as suas próprias posições. A socialdemocracia, a idéia do Mercosul, a integração dos imigrantes, o problema petrolífero, os mecanismos de controle da inflação etc. são temas aos quais Pasqualini teria se dedicado e sobre os quais Pedro Simon justifica a pertinência de "reler Pasqualini" e a coerência dos alinhamentos que ele mesmo adota.

Exemplar é a associação entre a implementação do Plano Real e a "influência pasqualinista" identificada no governo de Itamar Franco (do qual Simon foi líder no Senado). Segundo Simon, Pasqualini havia chamado atenção, "com visão profética", para "a cobertura de déficits [...] pelo estado", assinalando: "Foram precisos quarenta anos de inflação desenfreada para que o presidente Itamar Franco - discípulo à distância de Pasqualini e, por isso mesmo, muito preocupado com as questões sociais - instituísse esse controle como uma das bases do Plano Real" (idem:35).

A apresentação do "legado" e a constituição do "herdeiro" não poderiam deixar de contemplar a auto-apresentação de Pedro Simon como membro desse processo e a localização, nessa "família política", das siglas que liderou. Sua atuação como acadêmico no centro universitário, como coordenador da campanha a governador, ou sua participação em 
reuniões no apartamento de Pasqualini, em que jovens acadêmicos discutiam questões nacionais e discorriam sobre temas variados, são referidas como comprovação da sua vinculação ao personagem classificado de "mestre e exemplo". Por seu turno, aponta, como "legados de Pasqualini", a "consciência social", os "princípios" e a "moralidade". Retomando o discurso da especificidade, sustenta que sua influência pode ser observada em seus discípulos e na política do Rio Grande do Sul, "onde o trabalhismo se mantém vivo porque tem base ideológica. [...]. [e onde] não nos incomodamos em ficarmos ensangüentados porque já estamos acostumados à fatalidade. O que não aceitamos é a lama que desmoraliza" (idem:53). Além de demarcar traços de "especificidades da política gaúcha" e dos políticos do estado, enfatiza o papel do PMDB (como uma continuação do MDB) na sucessão dos valores identificados no "legado" de Pasqualini e do trabalhismo: "O PMDB gaúcho que emergiu do PTB é um partido de princípios, de idéias e, por isso, mesmo no regime arbitrário, nunca cedeu, jamais se atemorizou" (ibidem).

Nesse relato, evidencia-se o sentido de associação entre Pedro Simon-PMDB e Alberto Pasqualini-PTB. A proximidade social e de valores entre os protagonistas políticos de gerações diferentes é reclamada e acionada por diversos símbolos e sinais. Pedro Simon ressalta sua participação no círculo de adeptos das "idéias de Alberto Pasqualini", sem deixar de identificar elementos no "ícone da tradição" presentes na sua imagem, como a origem social ligada à imigração, o catolicismo, o nacionalismo e a defesa da socialdemocracia. Tais relações se amparam, ademais, na inscrição de ambos na "genealogia trabalhista", demonstrando-se a vinculação entre Pasqualini e Vargas por meio do PTB, entre PTB e seu sucedâneo no Rio Grande do Sul, o MDB, e entre esse e o PMDB liderado por Pedro Simon. Finalmente, essa inscrição é alicerçada na valorização da especificidade da política gaúcha e nos sinais de excepcionalidade dos seus líderes, pelos quais Pedro Simon procura se localizar e posicionar o PMDB. Nessa tripla associação, o autor da homenagem justifica sua condição ao mesmo tempo de porta-voz e de herdeiro do "legado".

\section{TARSO GENRO E A LEITURA MARXISTA: TRANSMISSÃO FAMILIAR, "SUPERAÇÃO DO POPULISMO" E AFIRMAÇÃO DE UM NOVO DISCURSO}

O percurso dos políticos da família Genro tem como origem, assumida e reivindicada, o "passado trabalhista". As ligações políticas e partidárias de Adelmo Genro, descendente de grandes proprietários rurais da 
Fronteira Oeste do Rio Grande do Sul, começam no período do declínio econômico do grupo familiar, por intermédio dos contatos e das relações herdadas com as "famílias" Vargas e Goulart (formada por grandes proprietários de terra) em São Borja. Adelmo Genro foi um dos coordenadores da primeira campanha eleitoral de João Goulart, que o levou à Assembléia Legislativa em 1947. A forte ligação de Adelmo Genro com João Goulart contrastava com suas divergências em relação à liderança de Leonel Brizola. Afora isso, as relações cultivadas com outro líder do PTB, originário da Metade Sul e seu contemporâneo de ginásio em Santa Maria, permitiram a sua nomeação como diretor da principal escola estadual de Santa Maria.

A atuação como professor e diretor do Colégio Manoel Ribas, o "Maneco", constituiu a base da reputação eleitoral e o trampolim para a carreira política de Adelmo Genro, que despontou na política eleitoral ao se eleger vereador e, posteriormente, vice-prefeito, de Santa Maria pelo PTB. O fato de ter sido cassado pelo regime militar quando ocupava a prefeitura interinamente transformou-o em um dos símbolos da "luta contra o regime militar" na cidade. Durante a ditadura, atuou como advogado e conquistou posições de liderança na seção local da Ordem dos Advogados do Brasil. Em 1980, filiou-se ao PMDB (assim como seus filhos), partido do qual foi presidente, chegando a concorrer ao cargo de vice-prefeito em 1982. Posteriormente, filiou-se ao PSB, sendo seu presidente de honra no Rio Grande do Sul.

Nas décadas de 1960 e 1970, seus filhos Tarso Genro (ex-presidente da Mocidade Trabalhista local) e Adelmo Genro Filho militaram no MDB e foram vereadores pelo partido. Adelmo Genro era nessa época uma das "referências" da oposição no município, e a "casa dos Genro", "território" de aglutinação de militantes, tendo como um de seus freqüentadores mais ilustres Pedro Simon. Além disso, Tarso Genro e Adelmo Genro Filho foram dirigentes da Juventude, órgão criado e apoiado por Pedro Simon, e de organizações de esquerda que atuavam no interior do MDB. Integraram no final da década a tendência Oposições Populares, liderada pelo presidente do Instituto de Estudos Políticos, Econômicos e Sociais - IEPES André Forster, formada por jovens lideranças e intelectuais com posições ligadas ao marxismo e que faziam uma "leitura crítica do trabalhismo", qualificando-o de "populista".

Assim, a notoriedade do grupo familiar e o ambiente político levaram dois dos seus filhos à militância partidária e eleitoral. Tarso Genro foi 
eleito vereador em 1968, e Adelmo Genro Filho em 1976, ambos pelo MDB. O primeiro iniciou sua militância política partidária na Ala Moça do PTB, após ter acompanhado as campanhas do pai na infância. Elegeu-se vereador pelo MDB em 1968, com vinte anos, e passou a fazer parte da Ala Vermelha do Partido Comunista do Brasil. Exilou-se no Uruguai no início da década de 1970 e, no retorno ao Brasil, passou a residir em Porto Alegre, atuando como advogado trabalhista, escritor, poeta e crítico literário. Nesse período, juntamente com seu irmão Adelmo Genro Filho, militou no PRC e ingressou no PMDB. Posteriormente, filiou-se ao PT, no qual liderou algumas tendências classificadas de "moderadas". Concorreu, em 1986, ao cargo de deputado federal constituinte; em 1988, a vice-prefeito (elegendo-se); em 1990, a governador (não se elegendo); e, em 1992 e 2000, a prefeito (sendo eleito). Depois de ter sido deputado federal, vice-prefeito, candidato a governador e duas vezes prefeito de Porto Alegre, concorreu em 2002 ao governo do Estado (perdendo no segundo turno). Seu último cargo ocupado foi o deministro da Educação.

Os artigos de Tarso Genro analisados nesta seção foram escritos no período de sua militância no $\mathrm{MDB}$, que teve como desdobramentos sua participação, inclusive como dirigente, no PRC, seu engajamento inicial no PMDB e, posteriormente, no PT, pelo qual foi deputado federal, vice-prefeito, prefeito de Porto Alegre (duas vezes) e candidato a governador do Rio Grande do Sul (em duas ocasiões). Considerado um dos principais intelectuais da "esquerda gaúcha" e a principal liderança das "correntes moderadas" do PT, os artigos examinados abaixo explicitam alguns usos da "tradição trabalhista" no processo de afirmação do protagonista no plano estadual.

Tarso Genro situa suas tomadas de posição mediante a combinação de definição da "herança" e de demarcação das formas de "superação", ou "críticas", dos "limites históricos e teóricos". Tal como se verifica nas narrativas de Miguel Bodea e Pedro Simon, as estratégias do agente buscam o "resgate" e a "evolução", imputando um sentido de continuidade com o passado e de legitimação dos seus recursos específicos de luta política. Há, assim, uma adequação (não necessariamente consciente ou calculada) entre a utilização de laços e móbiles de identificação prévios com os alinhamentos presentes e a distinção no espaço político. 
Os três textos tomados aqui, publicados em 1976, expressam as interpretações sobre o sentido da "herança trabalhista" para o MDB e, mais especificamente, para a "esquerda gaúcha", por meio da contextualização do papel de três lideranças dessa "tradição política": Getúlio Vargas, Alberto Pasqualini e João Goulart. No ensaio intitulado "Reflexões sobre o Populismo", Genro (1976a) sustenta que a especificidade do "líder populista brasileiro" Getúlio Vargas em relação aos seus congêneres latino-americanos - Juan Domingo Perón, Lázaro Cárdenas, José Battle e Haya de La Torre - residiria na "herança positiva" legada em termos de formação de um partido e no ideário nacionalista de Vargas. Já no artigo denominado "Alberto Pasqualini: Um Socialista no PTB?" o mesmo autor (1976c), procura estabelecer a "grandeza" e as "limitações" da contribuição da "pregação pasqualinista" e da sua "luta ideológica". Finalmente, no depoimento "Sobre um presidente" (Genro, 1976b), descreve sua convivência com João Goulart no Uruguai e expõe o "papel histórico" que, na sua acepção, o ex-presidente teria desempenhado.

Ao analisar o "líder populista" e o "getulismo" no Brasil, Tarso Genro (1976a:5) assume sua preocupação com a "conjuntura atual" ou "situação presente". Partindo da caracterização do populismo como "síntese [...] de interesses de classes sociais antagônicas, mas que, por interesse imediato, mantêm a luta amortecida", passa a comparar as experiências latino-americanas e os "testamentos" de seus líderes. Para ele, as grandes contribuições de Vargas residem nas "bases de um partido populista comprometido com determinadas noções fundamentais [...] do nosso tempo: a posição em relação à hegemonia econômica americana e a necessidade de fortalecer a indústria nacional" (ibidem). Classificando o "legado" partidário e o discurso nacionalista como a "herança positiva" e o "diferencial de Vargas e do PTB", indaga: "Poderá o MDB [...] herdar toda a força do trabalhismo e através de uma crítica modernizadora transformar-se num partido de massas, com predomínio dos interesses dos assalariados?" (ibidem). Propondo a defesa "em princípio" dos assalariados e uma aliança com a indústria nacional, além da adoção de uma postura de "revolta" em relação à "dependência desde a época colonial", postula: "perspectivas de formação de um partido democrático, $[\mathrm{em}]$ que o populismo serviria de base, mas não o deveria dominar" (ibidem). O "resgate" da especificidade do trabalhismo, da formação de uma base partidária e do discurso nacionalista é combinado com a afirmação de uma posição de cunho marxista, com base na qual reivindica a leitura e a orientação da "evolução". 
Essa estratégia de afirmação política e a lógica de autorização das suas posições a partir do domínio da linguagem marxista tornam-se mais claras no artigo sobre Pasqualini (Genro, 1976c). Nesse texto, Tarso Genro (idem:7) inicia sua argumentação sustentando a relevância histórica de Pasqualini no "seu tempo", devido à "pregação pasqualinista e à luta ideológica proporcionada pela sua militância anticapitalista e não socialista, mas socialdemocrata e modernizadora [que] foi a definição de amplos setores sociais em favor das reformas". Rejeitando a classificação do "teórico do trabalhismo" como "pensador socialista", a leitura das suas teses feita por Tarso Genro propõe que ele defendia uma "posição intermediária entre o socialismo e o capitalismo", aspecto que, na sua opinião, retrata uma linha política "bem mais avançada do que a linha do tradicional trabalhismo" (ibidem). Porém, a posição imputada a Pasqualini receberia a denominação de "utópica", em contraposição à posição "científica" fornecida pelo marxismo. A leitura crítica feita por Genro sobre a crença de Pasqualini em "um capitalismo sem dominância burguesa" ampara-se no pretenso conhecimento das "leis da história" possibilitado pelo marxismo, assinalando que o projeto político avaliado era "inviável em termos históricos" (ibidem).

"Sua grandeza é indiscutível, como são igualmente suas limitações, quiçá por ausência de um método científico para analisar as relações sociais. Mas a partir das suas teses pode ser montado um programa [...] desde que se adapte e se modernize alguns conceitos que hoje são chaves para uma análise concreta da nossa realidade histórica" (ibidem, ênfases minhas).

Nota-se como o caráter "indiscutível" do personagem e das suas limitações se baseia em uma avaliação que é enunciada e justificada mediante o domínio e o conhecimento de um "método científico". Além disso, a contribuição ("legado") das suas teses seria obra de atores capazes de modernizá-la e adaptá-la dentro de um "programa" dotado de "conceitos" e "chaves" de "análise da realidade histórica". Logo, Tarso Genro situa-se como intérprete do passado, do presente e do futuro e como condutor de um programa, alicerçando-se na sua capacidade de manipular e decifrar "realidades", "conceitos" e "métodos científi$\cos ^{\prime \prime}$.

As referências ao trabalhismo nos posicionamentos do futuro líder político apóiam-se também na proximidade pessoal e familiar com João Goulart. Em um depoimento igualmente publicado no semanário Informação - dirigido por seu irmão Adelmo Genro, seu primo Daniel 
Herz, sua cunhada Letícia Pasqualini e outras jovens lideranças de Santa Maria -, Tarso Genro expõe seu último encontro com o ex-presidente. Descreve, então, o percurso que o levara até a fazenda de Jango no Uruguai (já visitada em outro momento, segundo a narrativa), sua estada junto ao líder político exilado e o diálogo que travaram. Sobre a acolhida, enfatiza: "Sou recebido de forma paternal, como Jango recebia a quase todos. Pergunta pelo meu pai, tenta lembrar quando foi a última vez que falamos" (Genro, 1976b:11). Tarso Genro retrata a imagem, muito utilizada na apresentação de Jango, de um líder que trata as pessoas de "forma paternal", acrescentando os detalhes da amizade desse com seu pai (Adelmo Genro) e da convivência anterior de que desfrutara. Em relação ao teor do diálogo sobre a política brasileira, o depoimento centra-se na análise retrospectiva das razões e motivações que levaram ao golpe militar de 1964. Mais uma vez harmonizando a perspectiva de "crítica" com o "resgate", pontua: "critico-lhe sua postura populista, seu assessoramento irresponsável e a falta de clareza na relação que mantinha com as forças que lhe apoiavam" (ibidem). Ao interpretar o "papel histórico" do protagonista e do trabalhismo, apresenta-se como detentor do "saber" acerca do processo histórico. E conclui seu depoimento da seguinte forma:

"Na verdade, ele cumpriu um papel histórico que terminou por superar o populismo como estilo de liderança e como viabilidade para a reforma social. É verdade que as posições de Jango estavam além das possibilidades históricas concretas [...] mas o que é preciso ter claro é que Jango foi deposto por estas motivações imediatas que não subtraem da história seu posicionamento progressista. Afinal, algumas horas depois de sua queda foi revogada a 'lei de remessa de lucros' que limitava os lucros das empresas estrangeiras no Brasil". (ibidem, ênfases minhas)

A maneira como os relatos são organizados informa a relação do autor com os ícones. Getúlio Vargas é caracterizado pelo "espólio" partidário e nacionalista a ser superado e aprofundado pelos "setores progressistas" do MDB. A "herança positiva" da "trajetória de Vargas" é acionada com vistas às disputas internas ao MDB, às quais Tarso Genro passava a se dedicar como um dos líderes da corrente partidária Oposições Populares (situada à esquerda do espectro de posições existentes no interior do MDB e que aglutinava estudantes, professores e profissionais liberais). Na definição de Alberto Pasqualini proposta por Genro, o "teórico do trabalhismo" é objeto de interpretação e crítica no plano do "método científico" e dos "conceitos", em busca da "moderniza- 
ção" do "programa" e da "análise concreta da [...] realidade histórica". Por fim, na apresentação sobre João Goulart, aparece, por sua vez, ao lado da associação do líder com os anseios de reforma social, a proximidade entre as "famílias" e a intimidade desfrutada pela jovem liderança com uma das estrelas da política gaúcha. Esse capital de relações sociais derivado do meio familiar foi um recurso também utilizado por Genro na sua última campanha para o governo do Estado.

\section{CONSIDERAÇÕES FINAIS}

Os três intérpretes e as narrativas que os mesmos oferecem sobre a "tradição trabalhista" permitem desvendar a relação entre as transformações nos princípios de hierarquização social em pauta e as oposições entre critérios de construção e consagração de ascendentes políticos, assim como a afirmação de líderes políticos a partir do "resgate" de uma herança, acionando trunfos distintos ligados às suas origens sociais e aos seus itinerários.

Durante a segunda metade do século XX, é possível observar no Rio Grande do Sul a substituição das antigas elites advindas do "mundo da estância", e tributárias de uma forma de dominação calcada na mescla de funções militares, sociais e políticas, por elites políticas oriundas de grupos familiares ligados à imigração (alemã, italiana, síria e libanesa, entre outras) e ao catolicismo que passaram por significativas ascensões social e política (Grill, 2003). Nesse processo, ocorrem tensões, osmoses e interpenetrações que atravessam os grupos sociais e os próprios agentes (Phelippeau, 2002).

Como decorrência dessa diversificação social, há uma diferenciação quanto às estratégias de apresentação desses agentes e dos seus grupos familiares, e na concepção acerca da forma legítima de atuação política. Entre os descendentes de segmentos mais "tradicionais", são consagrados atributos como a inscrição dos antepassados nas principais disputas militares e políticas que marcaram a sociedade gaúcha no século XIX e primeira metade do século XX, enaltecendo-se os feitos heróicos e as qualidades como protagonistas de forma compatível com o que Coradini (1998a:227) caracterizou de "congruência entre uma estrutura de dominação social e um tipo de heroísmo militar, social e político". Procuram associar o exercício da atividade política ao domínio de uma "erudição humanista" e à capacidade de pronunciar-se sobre "temas genéricos". A apresentação da continuidade no meio político é 
classificada como decorrente de uma "vocação pública". Isso implica uma "situação [em que] o próprio exercício político é visto como doação [...] e [na qual] a utilização de recursos para o exercício político pode ser apresentada e vista como a 'doação' de alguém estatutariamente situado num nível mais elevado" (idem:232).

Entre os descendentes de segmentos que se estabeleceram socialmente na primeira metade do século XX e politicamente na segunda metade do século XX, predominam a valorização da ascensão social e política e dos investimentos escolares e o trabalho de reafirmação e redefinição da identidade étnica, religiosa e regional. Esses aspectos, por sua vez, passam a demarcar outros elementos. As tônicas empregadas são a ascensão social partindo de uma origem mais baixa ou as dificuldades enfrentadas pelos primeiros imigrantes. São utilizadas também uma série de expressões para definir a atuação política, as quais remetem a idéias genéricas que frisam o "trabalho comunitário", o "catolicismo" e o "atendimento". Os agentes, por sua vez, são classificados mediante critérios que englobam qualidades pessoais, envolvendo valores de obtenção de estima social, como o "empreendedorismo", o "pioneirismo", o "sucesso profissional", a "capacidade de trabalho" e o "espírito comunitário", entre outros.

Os intérpretes do trabalhismo e as narrativas por eles produzidas ao mesmo tempo expressam essa diversidade social e utilizam esses códigos para sustentar a "herança política". O argumento de Miguel Bodea situa a origem do trabalhismo na prática do castilhismo positivista isto é, nas lutas entre agentes advindos do "mundo da estância" - luta que evolui pela transmissão de uma concepção de política na qual se combinam e se complementam um "projeto de Estado" e uma "vocação doutrinária". O papel de Leonel Brizola seria avalizado por suas características pessoais, seus elos com Getúlio Vargas e João Goulart e seus feitos condizentes com a tradição "guerreira" e com a condição de "estadista" adquirida. E a função do próprio Bodea como "intelectual orgânico" seria garantida por suas qualidades intelectuais, e, conseqüentemente, doutrinárias, para recompor, no interior do PDT, a simbiose já identificada em outros momentos da história do trabalhismo.

Pedro Simon, por sua vez, exalta, a partir da figura de Alberto Pasqualini, valores como "pioneirismo" e "comunitarismo", ligados à imigração e ao catolicismo, que são agregados ao "legado partidário" e ao "nacionalismo". A origem social (vinculada à imigração), o itinerário 
(de ascensão social) e a carreira política (ligada a importantes momentos e líderes do trabalhismo) seriam, no que tange à continuidade de bases sociais e de condutas, exemplares e são fortalecidos pela carga simbólica conferida ao MDB na condição de sucedâneo do PTB e de agregador de grande parte das lideranças de origem trabalhista.

Por fim, Tarso Genro ressalta elementos comuns aos demais intérpretes, como o "nacionalismo" e o "legado partidário", mas sustenta a necessidade de sua superação. Para tanto, aciona dois trunfos de sua liderança. Em primeiro lugar, a vinculação pessoal e familiar (conquistadas devido à sua origem no "mundo da estância") com o trabalhismo e seus ícones (também presente em Leonel Brizola e Pedro Simon); em segundo lugar, o domínio, devido à sua formação, de uma linguagem de interpretação da realidade pretensamente dotada de "cientificida$\mathrm{de}^{\prime \prime}$ e capaz de renovar o legado (inclusive incorporando-o a outras organizações políticas), bem como de adaptá-lo às novas exigências fabricadas no espaço político e intelectual brasileiro.

Como se observa nessas estratégias de resgate dos "ícones e da tradição", ocorre um duplo movimento de atualização ou de renovação do "patrimônio" e de afirmação de sucessores. Os relatos e narrativas exaltam os feitos, realizações e atributos de antepassados e valores, que se procura associar à linhagem mitológica (Hastings, 1992) ou à genealogia simbólica (Abélès, 1992). Nesses mecanismos de consagração dos protagonistas políticos da "tradição", estão em pauta, então, para os herdeiros, a associação, a propagação dos valores e a caracterização da sua proximidade e semelhança com os antepassados, pelas quais, "nas lutas políticas [...], a própria imagem pode ser 'herdada' por 'associação' ou aproximação com os heróis consagrados" (Coradini, 1998a:232).

Uma série de trocas simbólicas se evidencia nessa linhagem mitológica ou genealogia simbólica. As alianças diacrônicas e sincrônicas entre ascendentes e descendentes e entre agentes da mesma geração política que se engajaram nas disputas políticas desde 1945 são ativadas por meio de relatos que visam a descrever as origens e a coerência da "tradição" e prescrever o destino e o caminho de forças políticas locais. Os intérpretes e porta-vozes da "tradição política" se fixam, desse modo, como mediadores entre o passado, o presente e o futuro. Executam igualmente uma ligação, interpretação e articulação entre as lógicas locais de disputa política e os códigos e ideologias que extrapolam essa 
dinâmica. Por fim, centralizam redes de seguidores, apontando novos "projetos de sociedade" e autorizando-se sobre seus recursos de vinculação aos ascendentes e à "linhagem". Nessa composição de elementos, afirmam seus trunfos pessoais e redefinem os conteúdos da "tradição política". A perenidade de determinados símbolos e as múltiplas combinações que revestem a "tradição política" são produto das estratégias e das leituras sucessivas e concorrentes desses mediadores entre períodos históricos, gerações, níveis de disputa e versões.

(Recebido para publicação em setembro de 2004)

(Versão definitiva em março de 2005))

\section{NOTAS}

1. Sobre o conjunto de "famílias de políticos" (suas origens sociais, itinerários e alinhamentos) vinculadas ao trabalhismo e que se destacaram no cenário político gaúcho na segunda metade do século XX em várias siglas, em diferentes momentos e em diversos níveis de atuação política, ver Grill (2003). A pesquisa mais ampla faz parte de uma tese de doutoramento defendida no Programa de Pós-Graduação em Ciência Política da Universidade Federal do Rio Grande do Sul - UFRGS, com o auxílio de bolsa fornecida pelo Conselho Nacional de Desenvolvimento Científico e Tecnológico- CNPq.

2. Sobre a composição de redes de famílias de políticos que aderiram à liderança de Leonel Brizola e ao PDT ou à liderança de Pedro Simon e ao PMDB, as rivalidades construídas ainda no período anterior a 1964 e as lealdades construídas e mantidas no MDB e seus desdobramentos no espaço político gaúcho, ver Grill (2003).

3. Sobre a importância de tais elementos para a afirmação do brizolismo, ver Sento-Sé (1999).

4. Sento-Sé demonstra o imbricamento de três registros na afirmação do PDT e do brizolismo ou do "projeto político" em pauta: a redefinição da tradição trabalhista, o nacionalismo e a aproximação com correntes socialistas ou socialdemocratas, por meio dos quais "a primeira confere ao projeto formulado um lastro histórico, [e] os dois outros fornecem instrumentos necessários para a formulação do projeto de futuro" (Sento-Sé, 1999:111).

5. Durante a década de 1960, dois grupos com origem no PTB, mas que divergiam quanto à postura em relação ao regime militar, se opunham no interior do MDB: o primeiro era liderado por Álvaro Petracco da Cunha, Lidovino Fanton e Wilmar Taborda; o segundo, por Heuser, Brusa Neto e Simon, entre outros. O primeiro grupo perdeu paulatinamente sua força no interior do MDB e somente voltou à cena com 0 retorno do exílio de Brizola e a fundação do PDT. O segundo grupo fortaleceu-se durante o regime militar e deu origem ao PMDB. 


\section{REFERÊNCIAS BIBLIOGRÁFICAS}

ABÉLÈS, Marc. (1992), “La Reference Familiale”, in C. Patriat e J. Parodi (orgs.), L'Hérédité en Politique. Paris, Economica, pp. 81-100.

BODEA, Miguel. (1979), A Greve Geral de 1917 e as Origens do Trabalhismo Gaúcho. Porto Alegre, L\&PM.

(1992), Trabalhismo e Populismo no Rio Grande do Sul. Porto Alegre, Editora da Universidade Federal do Rio Grande do Sul.

BROCHADO DA ROCHA, Otávio Caruso. (1979), “Prefácio”, in M. Bodea (org.), A Greve Geral de 1917 e as Origens do Trabalhismo Gaúcho. Porto Alegre, L\&PM Editora, pp. 7-14.

CORADINI, Odaci Luiz. (1998a), "Panteões, Iconoclastas e as Ciências Sociais”, in L. O. Felix et alii. (orgs.), Mitos \& Heróis: Construção de Imaginários. Porto Alegre, Editora da Universidade Federal do Rio Grande do Sul, pp. 219-240.

. (1998b), Elites Culturais e Concepções de Política no Rio Grande do Sul entre as Décadas de Vinte e Sessenta. Relatório de Pesquisa para o CNPq. Porto Alegre.

GENRO, Tarso Fernando. (1976a), “Reflexões sobre o Populismo". Informação, Porto Alegre, no 18, p. 5 .

. (1976b), "Sobre um Presidente". Informação, Porto Alegre, no 22, p. 11.

. (1976c), “Alberto Pasqualini: Um Socialista no PTB?". Informação, Porto Alegre, no 23, p. 5.

GRILL, Igor Gastal. (2003), Parentesco, Redes e Partidos: As Bases das Heranças Políticas no Rio Grande do Sul. Tese de Doutorado em Ciência Política, Porto Alegre, IFCH-UFRGS.

HALBWACHS, Maurice. (1994), Les Cadres Sociaux de la Mémoire. Paris, Albin Michel.

HASTINGS, Michel. (1992), “Le Mythe en Heritage”, in C. Patriat e J. L. Parodi (orgs.), L’Hérédité en Politique. Paris, Economica, pp. 235-248.

HÉLIAS, Yves. (1979), “Pour une Sémiologie Politique des Monuments aux Morts". Revue Française de Science Politique, vol. 29, no 4-5, pp. 739-759.

MOISÉS, José Álvaro. (1992), “Apresentação”, in M. Bodea (org.), Trabalhismo e Populismo no Rio Grande do Sul. Porto Alegre, Editora da Universidade Federal do Rio Grande do Sul, pp. 9-13.

NEIBURG, Frederico. (1997), Os Intelectuais e a Invenção do Peronismo. São Paulo, Editora da Universidade de São Paulo.

PHELIPPEAU, Eric. (2002), L'Invention de l'Homme Politique Moderne. Paris, Bélin.

POLLAK, Michel. (1989), "Memória, Esquecimento, Silêncio". Estudos Históricos, vol. 2, no 3, pp. 3-15.

SENTO-SÉ, João Trajano. (1999), Brizolismo: Estetização da Política e Carisma. Rio de Janeiro, Fundação Getulio Vargas Editora.

SIMON, Pedro. (1994), "Pasqualini, o Mestre e o Exemplo", in P. Simon (org.), Alberto Pasqualini: Obra Social e Política. Brasília, Editora do Senado Federal, pp. 19-53. 
LISTA DE SIGLAS DE PARTIDOS POLÍTICOS

MDB - Movimento Democrático Brasileiro

PCB - Partido Comunista Brasileiro

PDT - Partido Democrático Trabalhista

PMDB - Partido do Movimento Democrático Brasileiro

PRC - Partido Revolucionário Comunista

PRR - Partido Republicano Rio-Grandense

PSB - Partido Socialista Brasileiro

PT - Partido dos Trabalhadores

PTB - Partido Trabalhista Brasileiro 
ABSTRACT

Social Constituency and Interpreters of the "Labor Tradition" in Rio Grande do Sul, Brazil

This article examines the agents and narratives dedicated to celebrating the "Labor tradition" in the State of Rio Grande do Sul, Brazil. It begins by presenting the social origins and background of interpreters of this "legacy" who occupy different positions in the partisan political spectrum. It then proceeds to discuss the strategies for establishing continuity between the traditional icons and the individual and collective stances represented by these interpreters. The research then demonstrates the unvarying issues like valorization of the Labor partisan legacy, the nationalist rallying cries, and regional political specificity as well as the differences pertaining to the profiles of agents undertaking the historical research task. Based on the latter, the research also highlights the heroicization of the principal leaders and their link to political selection and recruitment processes at stake.

Key words: memory; political tradition; legacy; symbolic genealogy; narratives

\section{RÉSUMÉ}

Bases Sociales et Interprètes de la "Tradition Travailliste" au Rio Grande do Sul

Dans cet article, on examine les agents et les récits consacrés à la célébration de la "tradition travailliste" au Rio Grande do Sul, au Brésil. D'un côté, on présente les origines et les trajectoires sociales d'interprètes de l"'héritage" qui agissent à différents échelons politiques des partis. De l'autre, on montre les stratégies de construction d'une continuité entre les icones de la tradition et les prises de position individuelles et collectives que ces interprètes représentent. À partir de la recherche, on voit les invariances comme une mise en valeur de l'héritage du Parti Travailliste Brésilien, les emblèmes nationalistes et la spécificité de la politique régionale ainsi que les différences concernant le profil des agents engagés dans la constitution de la mémoire du parti. On constate aussi une tendance à considérer les principaux dirigeants comme des héros et on insiste sur leurs liens avec leurs processus de sélection et recrutement politique.

Mots-clé: mémoire; tradition politique; héritage; généalogie symbolique et récits 